\title{
ELEMEN PENDUKUNG ORGANIZASIONAL CITIZENSHIP BEHAVIOR
}

\author{
Umar Data*1, Susianah Mochtar $^{2}$ \\ STIEM Bongaya Makassar ${ }^{1,2}$ \\ e-mail: umar.data@ stiem-bongaya.ac.id ${ }^{1}$, susianahmochtar@gmail.com ${ }^{2}$
}

\begin{abstract}
Abstrak
Penelitian ini bertujuan untuk mengetahui elemen pendukung yang memengaruhi organizational citizenship behavior yakni motivasi kerja, komitmen organisasi, kompensasi dan kepuasan kerja. Pengumpulan data dilakukan dengan kuesioner yang dikirim langsung kepada sampel dengan menggunakan teknik accidental sampel dengan jumlah sampel 60 orang pegawai administrasi PT PLN (persero). Hasil penelitian menemukan bahwa motivasi kerja, komitmen organisasi, kompensasi dan kepuasan kerja signifikan memengaruhi organizational citizenship behavior.

Kata kunci : motivasi kerja, komitmen organisasi, kompensasi, kepuasan kerja, organizational citizenship behavior.
\end{abstract}

\begin{abstract}
This research wants to know that supporting elements that affect organizational citizenship behavior are work motivation, organizational commitment, compensation and job satisfaction. Data were collected through a questionnaire that was sent directly to the sample using accidental sampling technique with a total sample of 60 administrative employees of PT PLN (Persero). The results of the research found that work motivation, organization, compensation and job satisfaction have a significant effect on organizational citizenship behavior.

Keywords : Work motivation, organizational commitment, compensation, job satisfaction, organizational citizenship behavior.
\end{abstract}

\section{PENDAHULUAN}

Kemajuan perusahaan terkait erat dengan kualitas pegawai yang dimilikinya. Fakta banyaknya pegawai yang ingin keluar dari kerjaannya atau berpindah-pindah tempat kerja karena merasa tidak nyaman bahkan tidak puas dengan timbal balik yang perusahaan berikan membuat perusahaan juga harus menyadari arti pentingnya pegawai dalam perusahaan karena tanpa pegawai, tujuan organisasi perusahaan tidak dapat tercapai.

PT PLN (Persero) sebagai satunya-satunya perusahaan pemasok listrik di Indonesia terus berupaya menjadi perusahaan yang sehat dan berkembang. Kunci keberhasilan suatu perusahaan tergantung pada sumber daya manusia atau pegawainya. Perusahaan harus memiliki pegawai yang tidak hanya dapat menyelesaikan pekerjaan, tetapi pegawai yang memiliki peran tambahan untuk mencapai tujuan organisasi atau yang disebut dengan sumber daya manusia yang berkualitas, yang akan mendorong munculnya organizational citizenship behavior (OCB) agar dapat bersaing di era global (Rahawarin et al., 2020).

Teori pertukaran sosial adalah visi pegawai ketika mereka diperlakukan dengan baik dalam organisasi/perusahaan. Pegawai cenderung lebih aktif dalam organisasi. (Fung et al., 2012). Selain itu, teori pertukaran sosial menjelaskan bagaimana memelihara keserasian pertukaran sosial antara pegawai dan perusahaan. Pergantian berlaku saat dua pihak antara pegawai dan perusahaan dapat memberikan sesuatu berdasarkan kepercayaan. Ketika pegawai merasa bahwa mereka diperlakukan secara adil dan 
berpartisipasi dalam proses pengambilan keputusan dan mendapat sokongan dari atasan mereka, mereka cenderung loyal kembali kepada perusahaan (Lee et al., 2013).

Organizational citizenship behavior adalah perilaku tambahan yang bukan merupakan bagian dari tugas pekerjaan formal pegawai, tetapi yang mendukung operasi perusahaan yang efektif. Pegawai yang rela melakukan segalanya untuk kebutuhan perusahaan adalah peluang bagi organisasi. Pegawai yang mungkin bertanggung jawab atas pekerjaan yang dilakukan dan perusahaan mengharapkan untuk memberikan penghargaan atau ucapan selamat kepada pegawai atas pencapaiannya (Silitonga et al., 2020).

Elemen pendukung peningkatan organizational citizenship behavior yakni motivasi kerja. Pegawai yang memiliki motivasi kerja akan semangat menyelesaikan tugas dan tanggungjawabnya sehingga dapat memberikan kontribusi positif pada tercapainya tujuan perusahaan. Hasil penelitian (Danendra \& Mujiati, 2016) dan (Putra \& Sudibya, 2018) menunjukkan bahwa motivasi kerja berpengaruh positif dan signifikan terhadap organizational citizenship behavior.

Komitmen organisasi juga sebagai elemen pendukung peningkatan organizational citizenship behavior. Komitmen organisasi adalah kekuatan seorang individu untuk mengidentifikasi dirinya dalam suatu organisasi atau untuk berpartisipasi dalam suatu organisasi. Dengan komitmen yang tinggi terhadap organisasi, pegawai benar-benar bekerja keras sehingga dapat mendukung perkembangan perusahaan. Selain itu, pegawai yang sudah terikat secara emosional bersedia dan mampu mengambil tanggung jawab tambahan, seperti membantu rekan kerja lain yang membutuhkan, tanpa mengharapkan imbalan apa pun. Hasil penelitian (Sengkey et al., 2018) dan (Nurjanah et al., 2020) menemukan bahwa komitmen organisasi berpengaruh signifikan terhadap organizational citizen behavior.

Kompensasi juga sebagai elemen pendukung peningkatan organizational citizenship behavior. Dalam praktek manajemen sumber daya manusia, Kompensasi sangat penting bagi pegawai, karena gaji merupakan ukuran nilai pegawai atau standar kerja pegawai, keluarganya, dan masyarakat. Pimpinan hendaknya memperhatikan remunerasi yang diberikan kepada pegawai agar dapat meningkatkan semangat kerja dan terjadinya perilaku organizational citizenship behavior. Hasil penelitian (Danendra \& Mujiati, 2016) dan (Tan, 2017) menemukan bahwa kompensasi berpengaruh terhadap organizational citizen behavior.

Elemen lain yang mendukung peningkatan organizational citizenship behavior yakni kepuasan kerja pegawai. Ketika pegawai merasakan kepuasan terhadap pekerjaannya, maka pegawai tersebut akan bekerja maksimal menyelesaikan tugasnya bahkan dapat mengerjakan apa yang bukan menjadi tugasnya. Hasil penelitian (Widayanti \& Farida, 2016) dan (Nurafiah et al., 2019) menemukan bahwa kepuasan kerja berpengaruh terhadap organizational citizen behavior. Pegawai dapat merasakan kepuasan kerja jika lingkungan kerja mendukung hubungan baik antara atasan dengan pegawai, hubungan baik antara rekan kerja dalam menyelesaikan pekerjaan secara promosi dan perusahaan memberikan kesempatan promosi untuk pegawai yang berkinerja baik sehingga akan meningkatkan perilaku organizational citizenship behavior. Oleh karena itu, tujuan penelitian untuk mengetahui motivasi kerja, komitmen organisasi, kompensasi dan kepuasan kerja berpengaruh signifikan terhadap organizational citizenship behavior.

Hipotesis yang diajukan penelitian ini yaitu : 


\section{AkMen

$\mathrm{H}_{1}$ : Motivasi kerja berpengaruh positif dan signifikan terhadap Organizational Citezenship Behavior.

$\mathrm{H}_{2}$ : Komitmen Organisasi berpengaruh positif dan signifikan terhadap Organizational Citezenship Behavior.

$\mathrm{H}_{3}$ : Kompensasi berpengaruh positif dan signifikan terhadap Organizational Citezenship Behavior.

$\mathrm{H}_{4}$ : Kepuasan kerja berpengaruh positif dan signifikan terhadap Organizational Citezenship Behavior.

\section{METODE PENELITIAN}

Metode penelitian ini menggunakan saintifik. Populasi dalam penelitian ini adalah seluruh para pegawai administrasi PT PLN (Persero) Unit Induk Wilayah Sulselrabar sejumlah 150 orang. Teknik pengambilan sampel dalam penelitian ini menggunakan rumus Slovin, yaitu :

Dimana :

$$
n=\frac{N}{1+N(e)^{2}}
$$

$\mathbf{n}=$ Jumlah Sampel

$N=$ Jumlah Populasi

$\boldsymbol{e}=$ persentase kesalahan (akurasi) yang masih dapat ditoleransi atau diharapkan karena kesalahan pengambilan sampel $=10 \%$, dengan perhitungan sebagai berikut

$$
\begin{aligned}
& n=\frac{N}{1+N(e)^{2}} \\
& n=\frac{150}{1+150(0,1)^{2}} \\
& n=60
\end{aligned}
$$

Maka pengambilan sampel menggunakan teknik accidental sampling dengan total sampel sebanyak 60 orang pegawai administrasi.

Analisis inferensi yang digunakan dalam penelitian ini menggunakan alat statistik regresi linier berganda, rumusnya adalah

Keterangan :

$$
Y=a+\beta_{1} X_{1}+\beta_{2} X_{2}+\beta_{3} X_{3}+\beta_{4} X_{4+} e
$$

$\mathrm{Y}=$ Organizational Citezenship Behavior .

$\mathrm{X}_{1}=$ Motivasi kerja

$\mathrm{X}_{2}=$ Komitmen organisasi

$\mathrm{X}_{3}=$ Kompensasi

$\mathrm{X}_{4}=$ Kepuasan kerja

$\mathrm{a}=$ Bilangan Konstanta

$\beta=$ Koefisien Regresi

$\mathrm{e}=$ Residual Value

\section{HASIL DAN PEMBAHASAN}




\section{AkMen

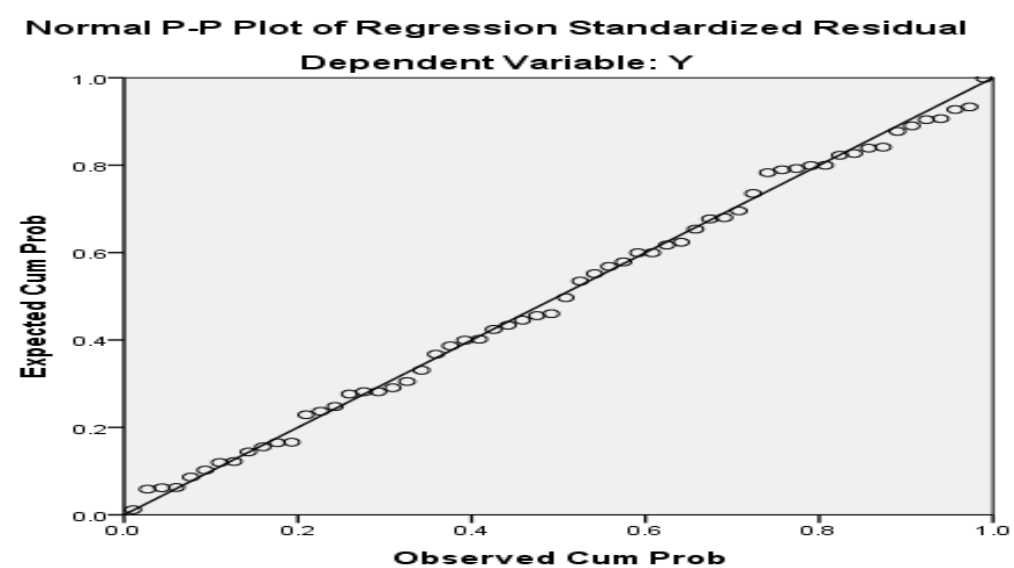

Gambar 1. Hasil Uji Normalitas

Sumber : Data Diolah SPSS V. 23.00 (2021)

Berdasarkan hasil uji probabilitas normal di atas, titik-titik tampak memanjang di sekitar diagonal, dan distribusinya mengikuti arus diagonal. Dengan demikian dapat disimpulkan bahwa model regresi dalam penelitian ini layak dan memenuhi asumsi normalitas.

Hipotesis heteroskedastisitas dari data uji adalah suatu kondisi dimana residual dari semua pengamatan dalam model regresi adalah serupa. Model regresi yang baik adalah tidak terdapat masalah heteroskedastisitas. Dalam penelitian ini digunakan uji heteroskedastisitas dengan metode uji Grafik, seperti terlihat pada gambar berikut:

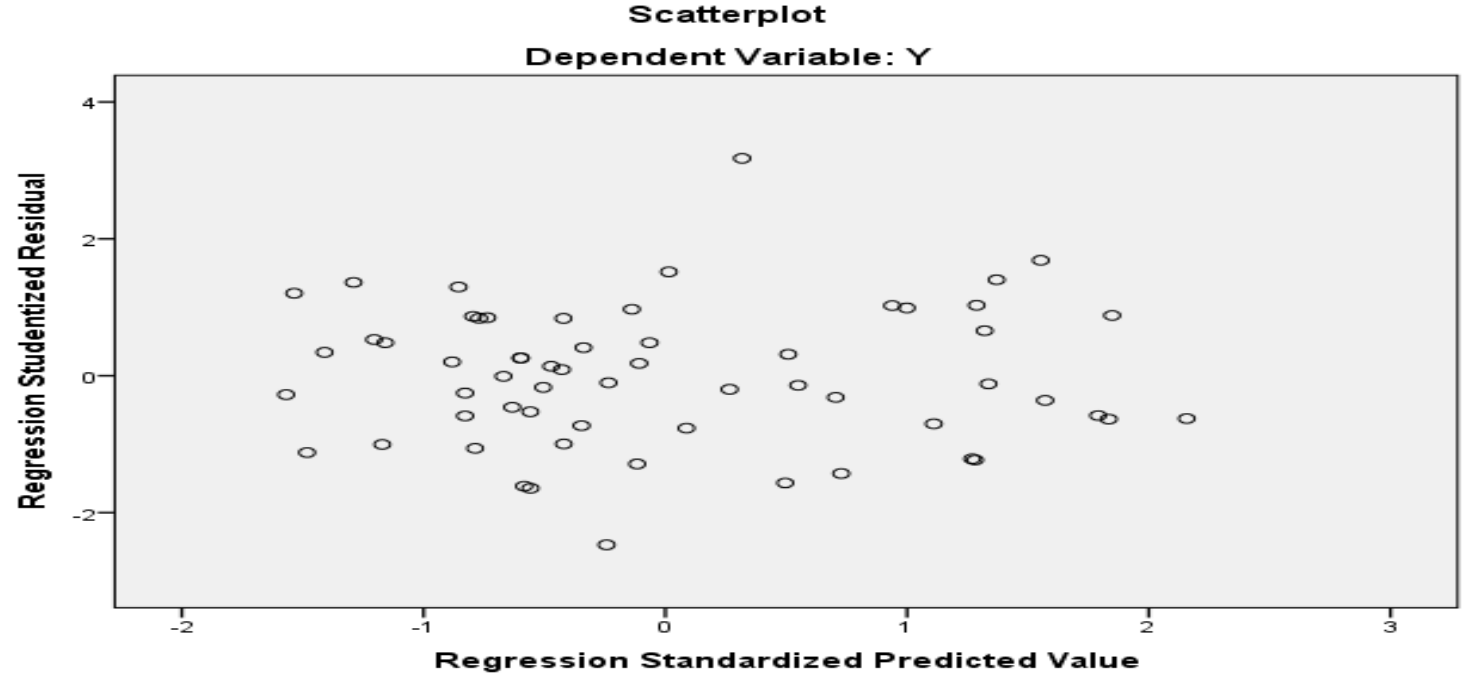

Gambar 2. Uji Heteroskedastisitas

Sumber : Data Diolah SPSS V. 23.00 (2021)

Dari hasil uji heteroskedastisitas di atas, terlihat bahwa tidak ada aturan yang jelas pada scatter plot. Titik-titik tersebut terdistribusi secara acak di atas dan di bawah angka 0 pada sumbu Y, dan dapat disimpulkan bahwa tidak terjadi masalah heteroskedastisitas.

Tabel 1. Hasil Uji Multikolinearitas 


\section{AkMen \\ Volume 18 Nomor 3 Desember 2021 \\ Hal. $321-330$ \\ e-ISSN : 2621-4377 \& p-ISSN : 1829-8524 \\ Hbmepage: https//e-jurnal.nobel.acid/index.php/akmen}

\begin{tabular}{llrr}
\hline & Tolerance & VIF \\
\hline 1 & Constant) & & \\
Motivasi Kerja &, 488 & 2,049 \\
Komitmen Organisasi &, 807 & 1,239 \\
Kompensasi &, 475 & 2,105 \\
Kepuasan Kerja &, 898 & 1,114 \\
\hline
\end{tabular}

a. Dependent Variable: Y

Sumber : Data diolah, SPSSV.23 (2021)

Dari hasil uji multikolinearitas data sebelumnya dapat diketahui bahwa Varians Inflating Factors (VIF) dari ketiga variabel bebas yaitu: motivasi kerja 2,049, komitmen organisasi 1,239, gaji 2,105, kepuasan kerja 1,114 dan VIF perusahaan. empat variabel bebas Nilainya kurang dari 10 , dan nilai toleransinya lebih besar dari 0,1 . Hal ini menunjukkan bahwa adanya tanda multikolinearitas pada persamaan yang dieksekusi dapat ditoleransi, sehingga tidak akan mengganggu hasil regresi.

Analisis koefisien determinasi adalah analisis yang digunakan untuk mengetahui kekuatan variabel selain variabel bebas yang diteliti untuk menjelaskan variabel terikat. Hasil pengujian koefisien determinasi ditunjukkan pada tabel berikut:

Tabel 2. Hasil Uji Koefisien Determinasi

\begin{tabular}{lrrrr}
\hline Model & R & R Square & Adjusted R Square & Std. Error of the Estimate \\
\hline 1 & $.709^{\mathrm{a}}$ & .503 & .467 & .15184 \\
\hline
\end{tabular}

a. Predictors: (Constant), X1, X2,X3, X4

b. Dependent Variable: Y

Sumber : Data diolah SPSS V.23.00 (2021)

Nilai R mengukur seberapa besar hubungan antara variabel dependen dan variabel independen. Berdasarkan hasil penelitian diperoleh nilai $\mathrm{R}$ sebesar 0,709 atau 70,90\% yang menunjukkan bahwa pengaruh motivasi kerja, komitmen organisasional, gaji dan kepuasan kerja terhadap perilaku kewargaan organisasi sebesar 70,90\%.

Nilai R-Square $\left(\mathrm{R}^{2}\right)$ atau nilai koefisien determinasi pada dasarnya merupakan ukuran kemampuan model dalam menjelaskan variasi variabel terikat. Nilai $\mathrm{R}^{2}$ adalah antara nol dan satu. Nilai $\mathrm{R}^{2}$ yang kecil berarti kemampuan variabel independen untuk menjelaskan perubahan variabel dependen sangat terbatas. Nilai yang mendekati 1 berarti bahwa variabel dependen memberikan informasi yang dibutuhkan untuk memprediksi semua variabel dependen.

Nilai $\mathrm{R}^{2}$ (R-squared) yang diperoleh adalah 0,503 atau 50,30\%. Hal ini menunjukkan bahwa variasi variabel bebas yang digunakan dalam model terbatas menjelaskan bahwa organizational citizenship behavior dipengaruhi oleh motivasi kerja, komitmen organisasi, gaji, dan kepuasan kerja sebesar 70,90\% yang berarti 29,10\% organizational citizenship behavior dipengaruhi oleh pekerjaan. motivasi dan komitmen organisasi, Gaji dan kepuasan kerja sebagai faktor-faktor lain di luar model penelitian ini.

Tabel 3. Hasil Uji Parsial (Uji t) 


\begin{tabular}{|c|c|c|c|c|c|c|}
\hline \multirow{2}{*}{\multicolumn{2}{|c|}{ Model }} & \multicolumn{2}{|c|}{$\begin{array}{l}\text { Unstandardized } \\
\text { Coefficients }\end{array}$} & \multirow{2}{*}{$\begin{array}{c}\text { Standardized } \\
\text { Coefficients } \\
\text { Beta }\end{array}$} & \multirow[b]{2}{*}{$\mathrm{t}$} & \multirow[b]{2}{*}{ Sig. } \\
\hline & & B & Std. Error & & & \\
\hline 1 & (Constant) & .661 & .536 & & 1.235 & .222 \\
\hline & Motivasi Kerja & .238 & .117 & 278 & 2.041 & .046 \\
\hline & $\begin{array}{l}\text { Komitmen } \\
\text { Organisasi }\end{array}$ & 171 & .072 & .253 & 2.388 & .020 \\
\hline & Kompensasi & .261 & .130 & .276 & 2.004 & .050 \\
\hline & Kepuasan Kerja & .195 & .091 & .215 & 2.138 & .037 \\
\hline
\end{tabular}

a. Dependent Variable: $Y$

Sumber : Data diolah SPSS V.23.00 (2021)

Tabel diatas menunjukkan hasil analisis regresi variabel motivasi kerja (X1), nilai $\mathrm{t}$ hitung variabel ini adalah 2,041. Tingkat signifikansinya adalah nilai koefisien regresi sebesar 0,046. T hitung 2,041> t tabel 1,673 memperkuat hasil ini. Hasil sebesar ini mengimplikasikan bahwa motivasi kerja (X1) berpengaruh positif dan signifikan terhadap organizational citizenship behavior, sehingga mendukung hipotesis.

Tabel di atas menunjukkan hasil analisis regresi variabel komitmen organisasi (X2), dan nilai t hitungnya adalah 2,388. Tingkat signifikansi adalah nilai koefisien regresi sebesar 0,020. Hasil ini diperkuat dengan nilai t hitung 2,388 > t tabel 1,673. Hasil ini berarti bahwa komitmen organisasi (X2) berpengaruh positif dan signifikan terhadap organizational citizenship behavior, dan hipotesis didukung.

Pada tabel di atas, menunjukkan hasil analisis regresi variabel kompensasi (X3), dan nilai t hitungnya adalah 2,004. Tingkat signifikansi adalah nilai koefisien regresi sebesar 0,050. Hasil ini diperkuat dengan nilai t hitung 2,004 > t tabel 1,673. Hasil ini berarti bahwa kompensasi (X3) berpengaruh positif dan signifikan terhadap perilaku organizational citizenship behavior, dimana hipotesis didukung.

Pada tabel sebelumnya, menunjukkan hasil analisis regresi variabel kepuasan kerja (X4), dan nilai t-hitungnya adalah 2,138. Tingkat signifikansi adalah nilai koefisien regresi sebesar 0,037. Nilai t hitung 2,138 >t tabel 1,673 memperkuat hasil ini. Hasil ini berarti bahwa kepuasan kerja (X4) berpengaruh positif dan signifikan terhadap organizational citizenship behavior, sehingga hipotesis didukung.

\section{Pembahasan}

\section{Pengaruh motivasi kerja terhadap organizational citizenship behavior.}

Hasil penelitian ini yang membuktikan bahwa motivasi kerja berpengaruh positif dan signifikan terhadap organizational citizenship behavior. Motivasi kerja yang tinggi dapat meningkatkan organizational citizenship behaviour. PT PLN (Persero) ingin meningkatkan organizational citizenship behavior tenaga outsourcing maka perlu memperhatikan tingkat motivasi yang dimiliki pegawai dalam bekerja dengan melihat sejauh mana kebutuhan pegawai dapat terpenuhi.

Motivasi merupakan faktor yang mendorong seseorang untuk melakukan suatu kegiatan tertentu, sehingga motivasi sering diartikan sebagai faktor yang mendorong perilaku seseorang, maka motivasi kerja memiliki pengaruh terhadap Organizational Citizenship Behaviour apabila motivasi dari masing-masing individu pegawai tinggi, 


\section{AkMen \\ Volume 18 Nomor 3 Desember 2021 \\ Hal. $321-330$ \\ e-ISSN : 2621-4377 \& p-ISSN : 1829-8524 \\ Hbmepage: https//e-jurnal.nobel.acid/index.php/akmen}

akan memberikan kontribusi berupa Organizational Citizenship Behaviour kinerja yang baik (Marayasa \& Faradila, 2019).

Hasil penelitian ini juga mendukung hasil penelitian (Danendra \& Mujiati, 2016), (Putra \& Sudibya, 2018) dan (Hendrawan, 2020) menunjukkan bahwa motivasi kerja berpengaruh positif dan signifikan terhadap organizational citizenship behavior. Motivasi kerja merupakan faktor pendorong perilaku seseorang (Nitawati, 2020). Motivasi kerja yang tinggi mampu memperoleh hasil kerja yang memuaskan dan berpengaruh terhadap kinerja pegawai (Themba \& Amin, 2021).

\section{Pengaruh komitmen organisasi terhadap organizational citizenship behavior.}

Hasil penelitian ini yang membuktikan bahwa komitmen organisasi berpengaruh positif dan signifikan terhadap organizational citizenship behavior. Komitmen organisasi pegawai yang tinggi akan membuat pegawai sungguh-sungguh menyelesaikan pekerjaannya sehingga akan menghasilkan kinerja yang baik. Perilaku ini pasti akan berdampak pada organizational citizenship behavior. Dibandingkan dengan pegawai yang tidak memiliki komitmen organisasi, pegawai yang memiliki komitmen organisasi pasti akan berperilaku berbeda untuk menghasilakn kinerja yang baik (Auliana \& Nurasiah, 2017).

Komitmen organisasi yang tinggi akan menyebabkan pegawai menunjukkan berbagai sikap dan perilaku positif, seperti misalnya menghindari tindakan, perilaku dan sikap merusak reputasi baik organisasi, loyalitas kepada pimpinan, kepada rekan kerja dan untuk bawahan, produktivitas tinggi, kesediaan untuk menyelesaikan konflik melalui musyawarah dan sebagainya (Fitria et al., 2015).

Hasil penelitian ini juga mendukung hasil penelitian Hasil penelitian(Sengkey et al., 2018), (Sengkey, Tewal, \& Lintong, 2018) dan (Ningsih, 2020) menemukan bahwa komitmen organisasi berpengaruh signifikan terhadap organizational citizen behavior. (Yanti \& Supartha, 2017) menyatakan bahwa semakin baik komitmen organisasi yang dirasakan pegawai maka organizational citizenship behavior dari pegawai akan semakin tinggi, sebaliknya pegawai dengan komitmen organisasi yang buruk maka organizational citizenship behavior dari pegawai akan semakin rendah.

\section{Pengaruh Kompensasi terhadap organizational citizenship behavior.}

Hasil penelitian ini yang membuktikan bahwa kompensasi berpengaruh positif dan signifikan terhadap organizational citizenship behavior. Kompensasi yang sesuai harapan dapat memotivasi dan mempertahankan pegawai untuk terus bekerja di PT PLN (Persero). Kompensasi merupakan fungsi SDM yang strategis dan memiliki dampak yang signifikan terhadap fungsi pekerjaan pegawai.

Kompensasi meliputi pembayaran tunai secara langsung, imbalan tidak langsung dalam bentuk benefit dan pelayanan (jasa), dan insentif untuk memotivasi pegawai agar tingkat produktifitas yang lebih tinggi adalah komponen yang sangat menentukan dalam hubungan kerja (Nitawati, 2020).

Hasil penelitian ini juga mendukung hasil penelitian (Tan, 2017), (Suhardi, 2019) dan (Ningsih, 2020) menunjukkan bahwa kompensasi berpengaruh positif dan signifikan terhadap organizational citizenship behavior. Semakin tinggi kompensasi yang diterima maka akan semakin kuat OCB pegawai (Danendra \& Mujiati, 2016).

\section{Pengaruh kepuasan kerja terhadap organizational citizenship behavior.}


Hasil penelitian ini yang membuktikan bahwa kepuasan kerja berpengaruh positif dan signifikan terhadap organizational citizenship behavior. Kepuasan pegawai terhadap pekerjaannya akan menyebabkan peningkatan organizational citizenship behavior, yang akan mempengaruhi kinerja mereka dalam organisasi. Kepuasan yang ingin dicapai meliputi kepuasan gaji, kepuasan promosi, kepuasan rekan kerja, kepuasan atasan, dan kepuasan kerja. Kinerja mencakup keseluruhan, termasuk peran atau perilaku tambahan yang biasa dikenal sebagai organizational citizenship behavior (Putrana et al., 2016).

Hasil penelitian ini juga mendukung temuan (Widayanti \& Farida, 2016), (Nurafiah et al., 2019) dan (Takdir \& Ali, 2020) menemukan bahwa kepuasan kerja berdampak pada organizational citizenship behavior. Dari perspektif manfaat perusahaan, kepuasan kerja yang tinggi berarti bahwa pegawai puas dan nyaman dengan kondisi lingkungan organisasi dan dihargai atas kerja keras mereka. Pegawai yang puas mungkin lebih patuh pada panggilan tugas karena ingin mengulang pengalaman positif yang mereka rasakan (Akbar et al., 2016).

\section{KESIMPULAN}

Berdasarkan hasil dan pembahasan penelitian dapat ditarik simpulan bahwa :

1. Motivasi kerja yang tinggi dapat meningkatkan organizational citizenship behaviour. PT PLN (Persero) ingin meningkatkan organizational citizenship behavior tenaga outsourcing maka perlu memperhatikan tingkat motivasi yang dimiliki pegawai dalam bekerja dengan melihat sejauh mana kebutuhan pegawai dapat terpenuhi.

2. Komitmen organisasi berpengaruh positif dan signifikan terhadap organizational citizenship behavior. Komitmen organisasi pegawai yang tinggi akan membuat pegawai sungguh-sungguh menyelesaikan pekerjaannya sehingga akan menghasilkan kinerja yang baik. Perilaku ini pasti akan berdampak pada organizational citizenship behavior.

3. Kompensasi berpengaruh positif dan signifikan terhadap organizational citizenship behavior. Kompensasi yang sesuai harapan dapat memotivasi dan mempertahankan pegawai untuk terus bekerja di PT PLN (Persero).

4. Kepuasan kerja berpengaruh positif dan signifikan terhadap organizational citizenship behavior. Kepuasan pegawai terhadap pekerjaannya akan menyebabkan peningkatan organizational citizenship behavior, yang akan mempengaruhi kinerja mereka dalam organisasi. Kepuasan yang ingin dicapai meliputi kepuasan gaji, kepuasan promosi, kepuasan rekan kerja, kepuasan atasan, dan kepuasan kerja.

\section{SARAN}

Penelitian selanjutnya diharapkan dapat memperluas sampel penelitian di PT PLN (Persero) cabang lain dan menambah aspek-aspek lain yang dapat memengaruhi organizational citizenship behavior.

\section{UCAPAN TERIMA KASIH}

Tim Penelitian ini mengucapkan terima kasih kepada Direktorat Riset dan Pengabdian Masyarakat, Deputi Bidang Penguatan Riset dan Pengembangan, Kementerian Riset dan Teknologi/Badan Riset dan Inovasi Nasional yang meberikan pendanaan melalui skema Penelitian Dosen Pemula tahun anggaran 2021 dan seluruh pihak yang mendukung pelaksanaan penelitian ini. 


\section{AkMen \\ Volume 18 Nomor 3 Desember 2021 \\ Hal. $321-330$ \\ e-ISSN : 2621-4377 \& p-ISSN : 1829-8524 \\ Homepage: https//e-jurnal.nobel.acid/index.php/akmen}

DAFTAR PUSTAKA

Akbar, F. H., Hamid, D., \& Djudi, M. (2016). Pengaruh Kepuasan Kerja Terhadap Komitmen Organisasional Dan Kinerja Pegawai (Studi pada Pegawai Tetap PG Kebon Agung Malang). Jurnal Administrasi Bisnis, 38(2), 79-88.

Auliana, S., \& Nurasiah, I. (2017). Penerapan Organizational Citizenship Behavior Dosen di STIE Bina Bangsa. Manajerial: Jurnal Manajemen Dan Sistem Informasi, 16(1), 149-162.

Danendra, A. A. N. B., \& Mujiati, N. W. (2016). Pengaruh Motivasi, Kompensasi Dan Komitmen Organisasional Terhadap Organizational Citizenship Behavior (OCB). Udayana University.

Fitria, R. M., Dewi, R. S., \& Febriana, S. K. T. (2015). Peranan Komitmen Organisasi Terhadap Organizational Citizenship Behavior Pada Perawat. Jurnal Ecopsy, 2(1).

Fung, N. S., Ahmad, A., \& Omar, Z. (2012). Work-Family Enrichment: It's Mediating Role In The Relationships Between Dispositional Factors And Job Satisfaction. International Journal of Academic Research in Business and Social Sciences, 2(11), 73.

Hendrawan, A. (2020). Motivasi Kerja Dan OCB (Organizational Citizenship Behavior) Pada Pegawai PT MK Semarang. Jurnal Administrasi Dan Kesekretarisan, 5(1), 7487.

Lee, U. ., Kim, H. K., \& Kim, Y. . (2013). Determinants of Organizational Citizenship Behavior and Its Outcomes. Global Business and Management Research. An International Journal, 5(1), 54-65.

Marayasa, I. N., \& Faradila, A. (2019). Pengaruh Motivasi Dan Disiplin Kerja Terhadap Kinerja Pegawai PT. Bank Dinar Indonesia. Jurnal Ekonomi Efektif, 2(1).

Ningsih, E. K. (2020). Pengaruh Komitmen, Kompetensi, Dan Budaya Organisasi Terhadap Organizational Citizhenship Behaviour (Ocb) Pegawai Puskesmas Bromo Medan. JRMB (Jurnal Riset Manajemen Dan Bisnis), 5(1), 75-88.

Nitawati, E. Y. (2020). Pengaruh Kompensasi, Motivasi, Dan Kepuasan Kerja Terhadap Organizational Citizenship Behavior (OCB)(Studi Kasus pada Pegawai Alfamart Team Coordinator I Surabaya). JPIM (Jurnal Penelitian Ilmu Manajemen), 5(1), 114.

Nurafiah, N., Syamsudduha, S. T., \& Rahman, U. (2019). Pengaruh Kepuasan Kerja terhadap Organizational Citizenship Behavior (OCB) di Kantor Kementerian Agama Kabupaten Bulukumba. Idaarah, 3(2), 216-226.

Nurjanah, S., Pebianti, V., \& Handaru, A. W. (2020). The influence of transformational leadership, job satisfaction, and organizational commitments on Organizational Citizenship Behavior (OCB) in the inspectorate general of the Ministry of Education and Culture. Cogent Business \& Management, 7(1), 1793521.

Putra, I., \& Sudibya, I. G. A. (2018). Pengaruh kepuasan kerja, komitmen organisasional dan motivasi kerja terhadap organizational citizenship behavior. E-Jurnal Manajemen Unud, 7(8), 4447-4474.

Putrana, Y., Fathoni, A., \& Warso, M. M. (2016). Pengaruh kepuasan kerja dan komitmen organisasi terhadap organizational citizenship behavior dalam meningkatkan kinerja pegawai pada PT. Gelora Persada Mediatama Semarang. Journal Of Management, 2(2).

Rahawarin, M. A., Zacharias, T., Yusriadi, Y., \& Rianti, M. (2020). Dimension Of Organizational Citizenship Behavior And Its Effect Toward Employees' Performance At Capital Investment And Licensing Service Office South Buru 
District. Humanities and Social Sciences Reviews. Humanities and Social Sciences Reviews, 8(2).

Sengkey, Y. M., Tewal, B., \& Lintong, D. C. (2018). Pengaruh Kepuasan Kerja dan Komitmen Organisasi Terhadap Organizational Citizenship Behavior (OCB) Pegawai Pada Kantor Sekretariat Daerah Kabupaten Minahasa Tenggara. Jurnal EMBA: Jurnal Riset Ekonomi, Manajemen, Bisnis Dan Akuntansi, 6(4).

Silitonga, N., Novitasari, D., Sutardi, D., Sopa, A., Asbari, M., Yulia, Y., Supono, J., \& Fauji, A. (2020). The Relationship Oftransformational Leadership, Organizational Justice And Organizational Commitment: A Mediation Effect Of Job Satisfaction. Journal of Critical Reviews, 7(19), 89-108.

Suhardi, S. (2019). Pengaruh Motivasi Kerja, Kompetensi, Lingkungan Kerja dan Kompensasi Terhadap Kinerja Pegawai PT. Asuransi Jiwa di Kota Batam Dengan Organizational Citizenship Behavior Sebagai Variabel Intervening. Jurnal Benefita, 4(2), 296-315.

Takdir, S., \& Ali, M. (2020). Pengaruh Komitmen Organisasi Dan Kepuasan Kerja Terhadap Organizational Citizenship Behaviors (OCB)(Studi Kasus Yapis Di Tanah Papua Cabang Kabupaten Jayawijaya). Jurnal Manajemen STIE Muhammadiyah Palopo, 6(1), 9-16.

Tan, R. (2017). Pengaruh Kompensasi dan Kepuasan Kerja terhadap Organizational Citizenship Behavior (OCB) melalui Motivasi Kerja sebagai variabel intervening pada 3H Motosport. Agora, 5(1).

Themba, O. S., \& Amin, A. (2021). Unsur Penentu Peningkatan Kinerja Manajerial Pt Pos Indonesia (Persero). Jurnal Ilmiah MEA (Manajemen, Ekonomi, \& Akuntansi), 5(1), 380-390.

Widayanti, R., \& Farida, E. (2016). Pengaruh kepuasan kerja dan komitmen organisasi terhadap organizational citizenship behavior (Study pada pegawai pemerintah kabupaten malang). Jurnal Aplikasi Manajemen, 14(4), 697-704. 